\title{
Photogeneration and transport of charge carriers in a porphyrin $p / n$ heterojunction
}

\author{
Tom J. Savenije* \\ Department of Molecular Physics, Agricultural University Wageningen, Dreyenlaan 3, Wageningen, The Netherlands \\ Ellen Moons, Gerrit K. Boschloo, and Albert Goossens \\ Department of Applied Inorganic Chemistry, Delft Technical University, Julianalaan 136, Delft, The Netherlands
}

Tjeerd J. Schaafsma

Department of Molecular Physics, Agricultural University Wageningen, Dreyenlaan 3, Wageningen, The Netherlands

(Received 24 July 1996; revised manuscript received 26 December 1996)

\begin{abstract}
Using impedance spectroscopy, the formation of a depletion layer is demonstrated upon contacting two films of different types of porphyrins. This depletion layer can be described in the same way as in a conventional $p / n$ heterojunction of inorganic semiconductors. From Mott-Schottky plots the doping concentration is found to be $\approx 10^{17} \mathrm{~cm}^{-3}$ for electropolymerized ZnTHOPP films and $\approx 10^{19} \mathrm{~cm}^{-3}$ for spin-coated $\mathrm{H}_{2}$ TMPyP films. Since the photocurrent action spectra are independent of the thickness of either of the layers, we conclude that charge separation and thus the photoactive part of the cell are confined to the interface of both layers. For charge collection, consecutive dissociation of the electron-hole pair competes with charge recombination. The internal field over the space charge layer causes the photoinduced charge carriers generated at the interface to drift through the bulk layer to the electrodes. [S0163-1829(97)05516-1]
\end{abstract}

\section{INTRODUCTION}

Organic dye molecules have recently gained interest as building blocks for optoelectronic devices, due to their chemical and electronic properties and high optical absorption. In this field of application, dyes have been mainly used as sensitizers for oxidic (nanocrystalline) semiconductors ${ }^{1-7}$ or as active components in heterojunction photocells. ${ }^{8-19}$ Previously, we reported the formation of a heterojunction, consisting of two types of porphyrin layers, of which one (the electron donor) is characterized by a low ionization potential and the other (the electron acceptor) by a high electron affinity. Upon illumination, photoinduced charge separation between both layers, followed by electron transport through the nonphotoactive bulk layer, results in a unidirectional photocurrent and an open circuit voltage $\left(O_{\mathrm{CV}}\right)$ of $\approx 0.5 \mathrm{~V}$.

Several mechanisms have been proposed for the photovoltaic effect in organic heterojunctions. One model is based on the finding that the photovoltaic effect occurs entirely at the interface between an organic dye and a second dye or a semiconductor. Then mainly the interfacial kinetics for charge separation and recombination mainly control the efficiency of the cell. Since the charge separation takes place at the interface, an extended internal electric field as in $p$ - $n$ junctions is not required. ${ }^{1,2}$

In an alternative model the organic dyes are assumed to form band structures similar to those in inorganic semiconductors. Depending on the nature of the dyes or additional doping, the organic layer has a $n$ - or $p$-type character. Upon contacting of an $n$ - and $p$-type layer, a depletion region is formed, where an exciton dissociates into free charge carriers by the internal electric field. ${ }^{20}$ The presence of a depletion region was invoked to explain the relatively large generated photocurrent. ${ }^{9-12,21}$ The photoactive zone in this band model stretches out across the depletion region, in contrast with the interface model where efficient photoinduced charge separation solely takes place at the interface of both organic dyes. Recently, however, the role of the depletion region in organic heterojunctions was reconsidered, ${ }^{13}$ since the contribution of the exciton diffusion length in the $p$ - $n$ model is not yet clear.

The formation of a depletion layer for molecular semiconductors has been demonstrated using impedance measurements on Schottky barrier systems, consisting of a porphyrinlike compound-metal contact. ${ }^{23-25}$ Such experiments have shown that a well-behaved Schotkky barrier is formed upon contacting the porphyrinlike material with, e.g., aluminum. In this work we demonstrate the presence of a depletion layer between two types of organic layers, using impedance measurements. A combination of this band model with the interface model based on the photocurrent action measurements can explain the observed photovoltaic properties.

\section{EXPERIMENTAL DETAILS}

Zinc tetra (hydroxyphenyl) porphyrin (ZnTHOPP) (Fig. 1) polymer films on ITO substrates were made by electro polymerization as previously published. ${ }^{8}$ The free base tetra (methyl-pyridinium) porphyrin $\left(\mathrm{H}_{2} \mathrm{TMPyP}\right)$ layer (Fig. 1) was applied by spin coating at $3000 \mathrm{rpm}$ a $10^{-3}$ mol solution in methanol onto the ZnTHOPP/ITO substrate. The samples were dried at $100{ }^{\circ} \mathrm{C}$ for $30 \mathrm{~min}$, stored in sealed vessels and kept in the dark.

The film thickness was measured by step profiling (Dektak 3030) mechanically made grooves in the film. UV-Vis absorption spectra of the porphyrin films were recorded using a Cary $5 e$ spectrophotometer (Varian Associates) and corrected for reflection by using a diffuse reflectance sphere.

The electrical top contact of the cell consists of a mercury 


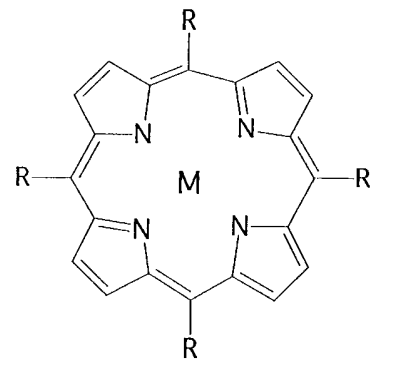

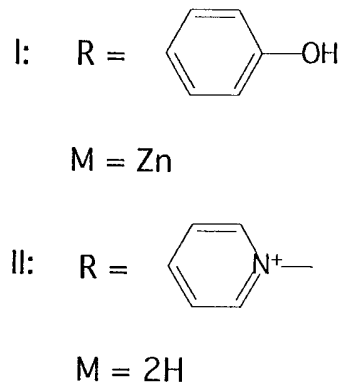

FIG. 1. Molecular structures of porphyrins: (i) $M=\mathrm{Zn}$, zinc tetra (4-hydroxyphenyl) porphyrin (ZnTHOPP) and (ii) $M=2 \mathrm{H}$, tetra (4-methyl pyridinium) porphyrin $\left(\mathrm{H}_{2} \mathrm{TMPyP}\right)$.

drop, connected to the sensing electrode, with an effective area $(A)$ of $0.78 \mathrm{~mm}^{2}$ integrated in a metal housing. ${ }^{8}$ For (photo) current measurements we used a potentiostat Autolab PGstat10 (Ecochemie) controlled by GPES3 software (Ecochemie) in combination with a $150-\mathrm{W}$ xenon light source (Spectral Energy) and a monochromator GM 252 (Spectral Energy). The complex impedances were recorded in the dark using a frequency response analyzer (Solartron model 1255) combined with an electrochemical interface (Solartron model 1286).

For analyzing the potential-dependent capacities, we made use of the Schottky equation (1). In the presence of a depletion layer, the concentration of ionized impurities in the space charge region $\left(N_{d}\right)$ and the built-in potential $\left(V_{\mathrm{BI}}\right)$ can be determined from ${ }^{22}$

$$
\frac{1}{C^{2}}=\left(\frac{2}{e \varepsilon_{r} \varepsilon_{0} N_{d}}\right)\left(V_{a}+V_{\mathrm{BI}}\right)
$$

where $C$ is the capacitance, $e$ the electronic charge, $\varepsilon_{r}$ the relative dielectric constant, $\varepsilon_{0}$ the permitivity of free space, and $V_{a}$ the applied potential.

Fermi energy levels were estimated by making use of a Kelvin probe technique. This technique is a noncontact method to determine the potential difference between the $\mathrm{Ag}$ reference electrode and the sample. For these measurements we used an electrostatic voltmeter (Trek 320B) with a highsensitivity probe (model 3250).

\section{RESULTS}

As previously shown, ${ }^{8}$ porphyrins equipped with four hydroxy groups, i.e., zinc tetra (4-hydroxy) phenyl porphyrin (ZnTHOPP) (Fig. 1), can be electropolymerized efficiently on ITO substrates. By changing the number of cyclic voltage scans, the thickness of the porphyrin films can be controlled between several $\mathrm{nm}$ and at least $100 \mathrm{~nm}^{26}$

First, the photoelectric characteristics of single porphyrin films on ITO substrates were examined to check whether a Schottky barrier was formed at the porphyrin/electrodes interfaces. Details of the different investigated junctions are presented in Table I. Figure 2(a) shows the dark $i / V$ characteristics of ITO/ZnTHOPP/Hg cells, differing in layer thickness. Upon illumination no significant short-circuit photocurrent $\left(i_{\mathrm{SC}}<1 \mathrm{nA}\right)$ or $V_{\mathrm{OC}}(<10 \mathrm{mV})$ is observed.

Figures 2(b) and 2(c) show the impedance plot at -1 and $1 \mathrm{~V}$, which can be fitted with an equivalent circuit consisting of a capacitance $(C)$ parallel to a resistance $\left(R_{p}\right)$ in series with a resistance $\left(R_{S}\right)$. Table II collects the fit results to these impedance plots. Since already at an analyzing frequency of $10 \mathrm{kHz}$ the current through $R_{p}$ cannot be neglected [Figs. 2(b) and 2(c)], the dependence of $C$ on the applied potential $\left(V_{a}\right)$ was calculated using an equivalent circuit, consisting of only $R_{p}$ and $C$, from

$$
C=\frac{-Z^{\prime \prime}}{\omega\left[\left(Z^{\prime}\right)^{2}+\left(Z^{\prime \prime}\right)^{2}\right]}
$$

where $Z^{\prime}$ and $Z^{\prime \prime}$ are the real and imaginary components of the impedance. The Mott-Schottky plot $\left(1 / C^{2}\right.$ vs $\left.V_{a}\right)$ is shown in Fig. 2(c).

For an ITO $/ H_{2} \mathrm{TMPyP}(d=25 \mathrm{~nm} / \mathrm{Hg}$ cell, the $i / V$ plot and the Mott-Schottky plot are shown in Fig. 3(a). Although the $i / V$ curves are strongly asymmetric, no $i_{\mathrm{SC}}$ or $V_{\mathrm{OC}}$ is observed upon illumination. Figure 3(b) shows the complex impedance spectrum at $V_{a}=0 \mathrm{~V}$, including a fit. In Fig. 3(a) the intercept of the tangent to the steep part with the $x$ axis yields $V_{\mathrm{BI}}=0.35 \mathrm{~V}$ for this cell. For $V_{a}>V_{\mathrm{BI}}$ the impedance plot deviates from a semicircle, and for fitting the data points a diffusion-limiting element has to be introduced in the equivalent circuit (data not shown).

A cell containing a heterojunction double layer in the configuration ITO/ZnTHOPP $(18 \mathrm{~nm}) / \mathrm{H}_{2} \mathrm{TMPyP} / \mathrm{Hg}$, shows a clearly asymmetric $i / V$ plot [Fig. 4(a)]. Note that contrary to

\begin{tabular}{|c|c|c|c|c|c|c|c|}
\hline $\begin{array}{l}\text { Cell } \\
\text { ITO/or/Hg }\end{array}$ & $\begin{array}{l}\text { Outer diameter } \\
(\lambda \text { in } \mathrm{nm})\end{array}$ & $\begin{array}{c}d^{\mathrm{a}} \\
\text { layer } \\
(\mathrm{nm})\end{array}$ & $\begin{array}{c}E_{\mathrm{PA}}^{\mathrm{b}}{ }^{2} \mathrm{NH} \\
\text { (V) }\end{array}$ & $\begin{array}{c}E_{F}(\text { vs vacuum }) \\
(\mathrm{eV})\end{array}$ & $C(\mathrm{nF})$ & $\begin{array}{c}N_{d} \\
10^{-18} \\
\left(\mathrm{~cm}^{-3}\right)\end{array}$ & $\epsilon_{r}^{\mathrm{c}}$ \\
\hline ZnTHOPP & $\begin{array}{l}0.084 \\
(564)\end{array}$ & 18 & 0.85 & 5.3 & 1.6 & & 4.2 \\
\hline $\mathrm{H}_{2} \mathrm{TMPyP}$ & $\begin{array}{l}0.095 \\
(529)\end{array}$ & 25 & $\approx 1.5$ & 4.7 & 32 & & \\
\hline ZnTHOPP/H ${ }_{2}$ TMPyP & & 18 & & & 1.4 & 0.31 & 3.8 \\
\hline
\end{tabular}

TABLE I. Characteristics of the different cells measured in this work.

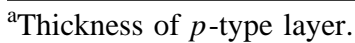

${ }^{\mathrm{b}}$ Anodic peak potential from Ref. 43. (NHE denotes normalized hydrogen electrode.)

${ }^{\mathrm{c} C}$ Calculated using Eq. (4) for ZnTHOPP layer. 

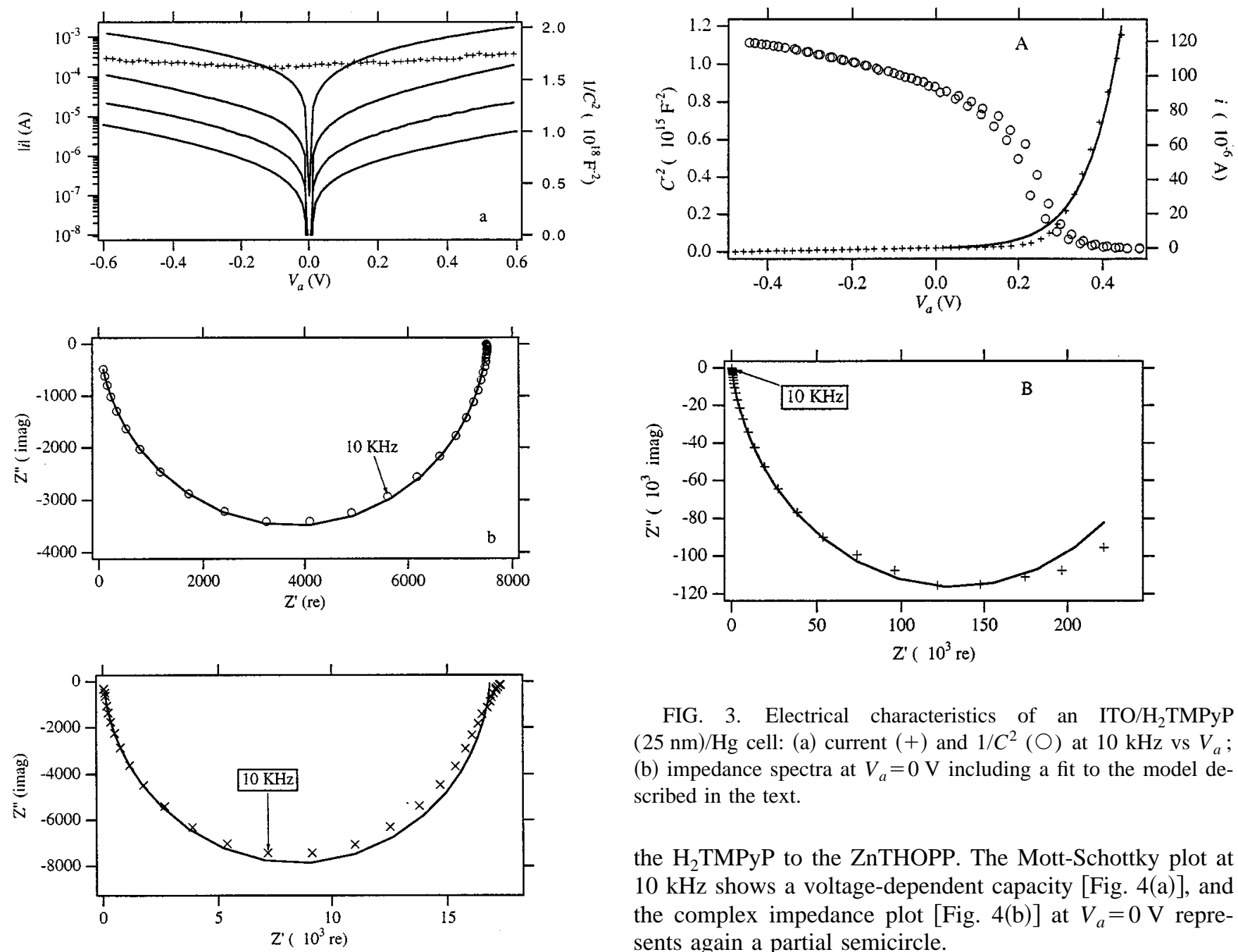

FIG. 2. Electrical characteristics of ITO/ZnTHOPP/Hg cells: (a) dark current vs $V_{a}$ for cells with layer thickness of $18 \mathrm{~nm}$ (bottom), $15,8.7 \mathrm{~nm}$, and $2.7 \mathrm{~nm}$ (top), and the Mott-Schottky plot (+) $\left(1 / C^{2}\right.$ vs $\left.V_{a}\right)$ at $10 \mathrm{kHz}$ for a cell with an $18-\mathrm{nm}$ porphyrin layer; impedance spectrum at (b) $V_{a}=-1 \mathrm{~V}$ and (c) $V_{a}=-1 \mathrm{~V}$ including a fit to the model described in the text.

an $\mathrm{ITO} / \mathrm{H}_{2} \mathrm{TMPyP} / \mathrm{Hg}$ cell, where a forward bias is applied, when the $\mathrm{Hg}$ electrode is positive with respect to ITO, now a forward bias applies to the $\mathrm{Hg}$ electrode negative with respect to ITO. This implies that under forward conditions electrons flow from the $\mathrm{Hg}$ electrode to the ITO, i.e., from

FIG. 3. Electrical characteristics of an ITO/ $\mathrm{H}_{2} \mathrm{TMPyP}$ $(25 \mathrm{~nm}) / \mathrm{Hg}$ cell: (a) current $(+)$ and $1 / C^{2}(\bigcirc)$ at $10 \mathrm{kHz}$ vs $V_{a}$; (b) impedance spectra at $V_{a}=0 \mathrm{~V}$ including a fit to the model described in the text.

the $\mathrm{H}_{2}$ TMPyP to the ZnTHOPP. The Mott-Schottky plot at $10 \mathrm{kHz}$ shows a voltage-dependent capacity [Fig. 4(a)], and the complex impedance plot [Fig. 4(b)] at $V_{a}=0 \mathrm{~V}$ represents again a partial semicircle.

Figure 5 shows the $i / V$ curves under illumination and in the dark for an ITO/ZnTHOPP/ $\mathrm{H}_{2} \mathrm{TMPyP} / \mathrm{Hg}$ cell. The photocurrent is anodic at $V_{a}=0 \mathrm{~V}$, indicating that the direction of electron transport is from ZnTHOPP to $\mathrm{H}_{2}$ TMPyP. The generated photocurrent $\left(i_{\mathrm{ph}}\right)$ at $V_{a}=0 \mathrm{~V}$ depends on the light intensity $I_{0}$ as $i_{\mathrm{ph}} \infty I_{0}^{m}$, with $m=0.7-0.85$. In Fig. 5(a) the intercept of the tangent to the steep part with the $x$ axis yields $V_{\mathrm{BI}}=-0.58 \mathrm{~V}$ for this porphyrin heterojunction. The maximum recorded $V_{\mathrm{OC}}$, however, is smaller, i.e., $-0.42 \mathrm{~V}$ (Fig. 5).

Figures 6(a) and 6(c) show the absorption spectra of ITO/ZnTHOPP $/ \mathrm{H}_{2} \mathrm{TMPyP} / \mathrm{Hg}$ cells in the region between 500 and $700 \mathrm{~nm}$ with different thicknesses of both individual

TABLE II. Results from fitting the dispersion spectra. $\chi^{2}<2.8 \times 10^{-3}$ for all fits.

\begin{tabular}{lccccc}
\hline \hline Cell & $V_{a}$ & $d^{\mathrm{a}}$ & $R_{s}$ & $R_{p}$ & $C$ \\
ITO/org/Hg & $(\mathrm{V})$ & $(\mathrm{nm})$ & $(\mathrm{k} \Omega)$ & $\begin{array}{c}C \\
(\mathrm{nF})\end{array}$ \\
\hline ZnTHOPP & -1.0 & 18 & 0.02 & $8 \mathrm{~K}$ & $1.6(0.96)$ \\
ZnTHOPP & 1.0 & 18 & 0.04 & $17 \mathrm{~K}$ & $1.5(0.96)$ \\
$\mathrm{H}_{2}$ TMPyP & 0.0 & 25 & 0.1 & $0.3 \mathrm{ml}$ & $63(0.92)$ \\
ZnTHOPP/H 2 TMPyP & 0.7 & 18 & 0.1 & $0.7 \mathrm{ml}$ & $2.8(0.94)$ \\
\hline \hline
\end{tabular}

Thickness of $p$-type layer.

${ }^{\mathrm{b}}$ Approximate thickness $5 \mathrm{~nm}$. 

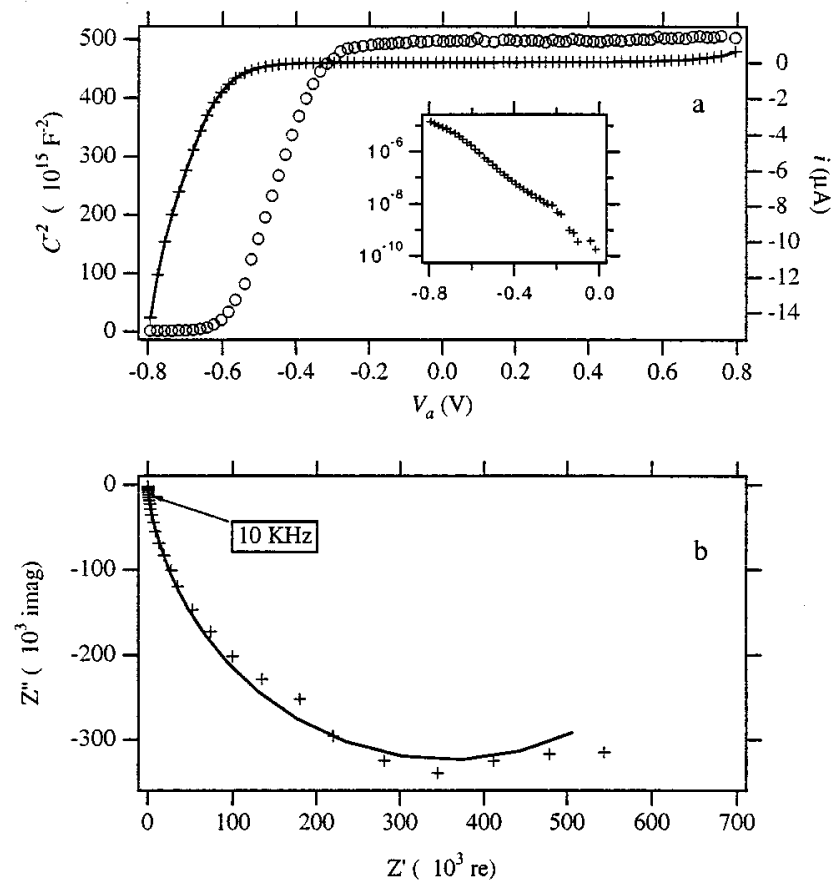

FIG. 4. Electrical characteristics of an ITO/ZnTHOPP $(18 \mathrm{~nm}) / \mathrm{H}_{2} \mathrm{TMPyP} / \mathrm{Hg}$ cell: (a) dark current $(+)$ and $1 / C^{2}(\bigcirc)$ at 10 $\mathrm{kHz}$ vs $V_{a}$; the inset shows the current on a logarithmic scale; (b) impedance spectra at $V_{a}=0.7 \mathrm{~V}$ including a fit to the model described in the text.

layers. Figures 6(b) and 6(d) present the corresponding photocurrent action spectra at $V_{a}=0 \mathrm{~V}$. The photocurrent response is expressed as the incident photon to current conversion efficiency (IPCE) by

$$
\mathrm{IPCE}=\frac{i_{\mathrm{ph}}}{e I_{0}} 100 \%,
$$

where $e$ is the electronic charge and $I_{0}$ the number of incident photons $\mathrm{s}^{-1} \mathrm{~cm}^{-2}$. As a result of considerable overlap between the absorption spectra of ZnTHOPP and $\mathrm{H}_{2}$ TMPyP, the porphyrin layers cannot be excited separately. However, comparing the absorption spectra with the photocurrent action spectra, it can be seen that both layers

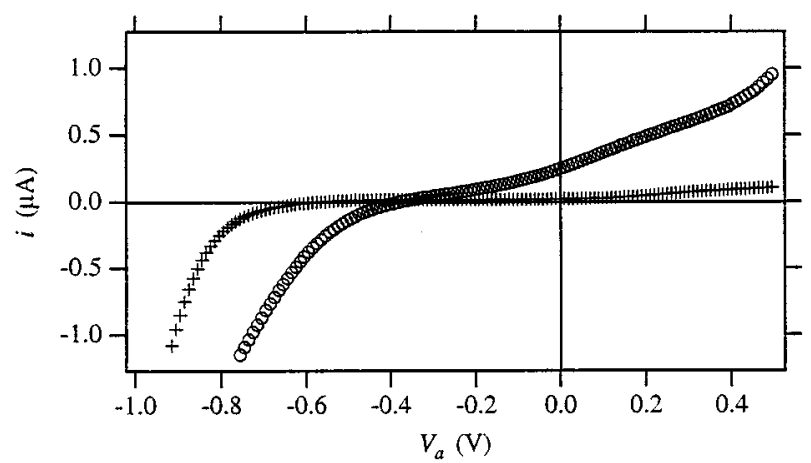

FIG. 5. $i / V$ plots of an ITO/ZnTHOPP $(15 \mathrm{~nm}) / \mathrm{H}_{2} \mathrm{TMPyP} / \mathrm{Hg}$ cell with an effective area of $0.78 \mathrm{~mm}^{2}$ under illumination with $13 \mathrm{~m} \mathrm{~W} \mathrm{~cm}^{-2}$ at $440 \mathrm{~nm}(\bigcirc)$ and in the dark $(+)$.

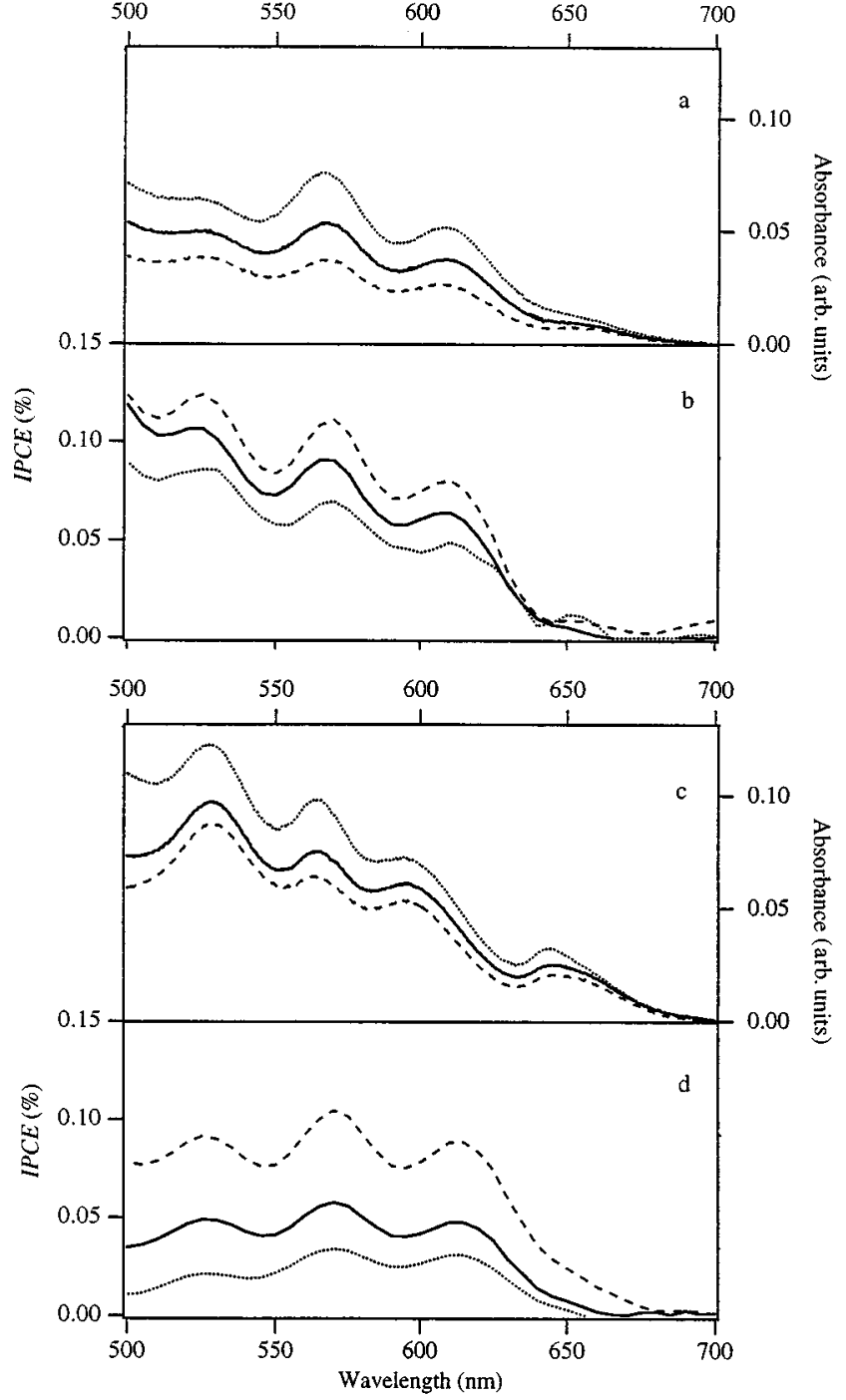

FIG. 6. Absorption spectra (a), (c) and short-circuit action spectra expressed as the IPCE (b), (d) of various ITO/ZnTHOPP/ $\mathrm{H}_{2} \mathrm{TMPyP} / \mathrm{Hg}$ cells with different thickness of the organic layers. Thickness of the ZnTHOPP layer: $6.4 \mathrm{~nm}$ (dashed line), $11 \mathrm{~nm}$ (solid line) $18 \mathrm{~nm}$ (dotted line); thickness of $\mathrm{H}_{2}$ TMPyP layer: (a),(b): $5 \mathrm{~nm}$, (c),(d) $19 \mathrm{~nm}$.

give rise to a photocurrent, considering the presence of pronounced $\mathrm{ZnTHOPP}$ and $\mathrm{H}_{2}$ TMPyP $Q$ bands at 565 and 520 $\mathrm{nm}$, respectively, in the action spectrum. Increasing the thickness of either the ZnTHOPP layer or the $\mathrm{H}_{2}$ TMPyP layer or both results in a decrease of the photocurrent.

The Fermi energy $\left(E_{F}\right)$ levels of ZnTHOPP and $\mathrm{H}_{2}$ TMPyP are collected in Table I. For ZnTHOPP, $E_{F}$ $\approx 5.3 \mathrm{eV}$, close to the value predicted by the oxidation potential of the porphyrin monomer in solution. ${ }^{8}$ The Fermi level of the $\mathrm{H}_{2}$ TMPyP layer at $4.7 \mathrm{eV}$ indicates that it positioned halfway in the energy band gap.

\section{DISCUSSION}

Illumination of cells consisting of two porphyrin layers with appropriate redoxpotentials on top of each other results in a photoinduced unidirectional charge separation. By contrast, separate layers do not show a photovoltaic response. ${ }^{8}$ 
As already mentioned, two different models, i.e., the formation of a space charge region as in a conventional $p / n$ junction and the interfacial model, have been proposed to describe the cell characteristics. First, we discuss the presence of possible barriers between both organic layers and/or between one of the organic layers and the electrodes using impedance spectroscopy.

\section{A. Impedance measurements}

For the ITO/ZnTHOPP/Hg cells the dark current depends on $V_{a}$ with $|i|_{\sim}\left|V_{a}\right|^{k}$, with $k=2.8-3.3$. Furthermore, decreasing the thickness of the organic layer results in a nonlinear increase of the dark current. These results including the almost-constant capacitance of the cell in the applied potential region are a strong indication of a space-chargelimited current. ${ }^{22}$ The capacitance at $10 \mathrm{kHz}$ is found to be almost voltage independent. This observation and the almost symmetrical $i / V$ curves strongly indicate that no barriers are present at either interface. The capacitance is thus geometrically determined. Using

$$
C=\frac{\varepsilon_{0} \varepsilon_{r} A}{d},
$$

the relative dielectric constant $\varepsilon_{r}$ of the porphyrin layer can be determined, where $A$ is cell area and $d$ the layer thickness. For a ZnTHOPP layer we find $\varepsilon_{r} \approx 4.2$, similar to $\varepsilon_{r}$ values reported for thin films of phthalocyanines. ${ }^{20}$

In contrast with the above findings, an ITO/ $\mathrm{H}_{2} \mathrm{TMPyP} / \mathrm{Hg}$ cell exhibits a potential-dependent capacitance and an asymmetric $i / V$ curve (Fig. 3). The Mott-Schottky plot resembles that of a melat-insulator-semiconductor-like (MIS-like) structure. In the potential range of $0.2-0.35 \mathrm{~V}$, the current shows Schottky barrier behavior. ${ }^{22}$ This indicates the existence of an $n$-type band bending for electrons in the porphyrin layer at the $\mathrm{H}_{2} \mathrm{TMPyP} / \mathrm{Hg}$ interface or a $p$-type band bending at the ITO/ $\mathrm{H}_{2}$ TMPyP interface. The Kelvin probe measurements indicate, however, that a $p$-type contact at the ITO $\left(E_{F}=5.2 \mathrm{eV}\right), \mathrm{H}_{2}$ TMPyP $\left(E_{F}=4.7 \mathrm{eV}\right)$ interface is energetically not feasible.

Using Eq. (1), the product $\varepsilon_{r} N_{d}$ was determined from the $1 / C^{2}$ vs $V_{a}$ plot (Fig. 3). For an $\mathrm{ITO} / \mathrm{H}_{2} \mathrm{TMPyP} / \mathrm{Hg}$ cell this plot exhibits two regions with different slopes. Since $\varepsilon_{r}(\mathrm{ITO})=8.9$ and $N_{d}>10^{20} \mathrm{~cm}^{-3}$ for this kind of ITO, ${ }^{27}$ $\varepsilon_{r} N_{d}>8.9 \times 10^{20} \mathrm{~cm}^{-3}$. The value of $\varepsilon_{r} N_{d}=4.5$ $\times 10^{21} \mathrm{~cm}^{-3}$ determined from the slope of $1 / C^{2}$ in the potential region 0.0 to $-0.4 \mathrm{~V}$ thus indicates a band bending in the ITO substrate. The slope in the potential range between 0.35 and $0.2 \mathrm{~V}$ yields $\varepsilon_{r} N_{d}=4.0 \times 10^{20} \mathrm{~cm}^{-3}$, which applies to the porphyrin layer. Such an interpretation for very thin semiconductor layers sandwiched between metallike contacts has been reported previously. ${ }^{28}$ Since the spin-coating method does not produce homogeneous layers, pinholes cannot be excluded. Therefore systematic variation of the film thickness could not be used for further analysis of these MISlike structures.

An ITO/ZnTHOPP/ $\mathrm{H}_{2} \mathrm{TMPyP} / \mathrm{Hg}$ cell exhibits also a potential-dependent capacitance and an asymmetric $i / V$ plot, but now the currents at a forward bias appear at negative applied potentials, in contrast to an $\mathrm{ITO} / \mathrm{H}_{2} \mathrm{TMPyP} / \mathrm{Hg}$ cell.
Again, the $1 / C^{2}$ vs $V_{a}$ plot shows two different slopes, yielding $\varepsilon_{r} N_{d}=1.2 \times 10^{18} \mathrm{~cm}^{-3}$ and $\varepsilon_{r} N_{d} \approx 1 \times 10^{20} \mathrm{~cm}^{-3}$, respectively. Since we expect an $n$-type barrier at the $\mathrm{H}_{2} \mathrm{TMPyP} / \mathrm{Hg}$ interface and an Ohmic contact at the ITO/ ZnTHOPP interface, the only possibility to explain these characteristics is the formation of a barrier between both porphyrin layers. Based on the forward bias $<0 \mathrm{~V}$ and the exponential dependence of the dark current on the applied potential, we conclude that the $\mathrm{ZnTHOPP} / \mathrm{H}_{2} \mathrm{TMPyP}$ binary layer acts as a $p / n$ heterojunction. This is consistent with the Fermi energy levels of 5.3 and $4.7 \mathrm{eV}$ for the ZnTHOPP and H2TMPyP layers, respectively.

Since both porphyrin layers are chemically different and have been deposited by different methods, $N_{d}$ and to a smaller extent $\varepsilon_{r}$ are expected to be different for both layers. From the measurements on $\mathrm{ITO} / \mathrm{H}_{2} \mathrm{TMPyP} / \mathrm{Hg}$ cells, $N_{d}$ is estimated to be $\approx 10^{19} \mathrm{~cm}^{3}$. Therefore we ascribe the capacity change in the potential range -0.58 to $-0.23 \mathrm{~V}$ (Fig. 4) to the increasing depletion of the ZnTHOPP layer. Above $-0.23 \mathrm{~V}$ the complete ZnTHOPP layer is depleted. At $V_{a}$ $=-0.23 \mathrm{~V}$ the capacity of the ITO/ZnTHOPP/ $\mathrm{H}_{2} \mathrm{TMPyP} / \mathrm{Hg}$ cell is found to be $1.4 \mathrm{nF}$ (Fig. 4), and using Eq. (6), $\varepsilon_{r}$ is calculated to be 3.8 , close to its independently determined value for an ITO/ZnTHOPP/Hg cell. Using Eq. (1), we find $N_{d}=3.1 \times 10^{17} \mathrm{~cm}^{-3}$ for the ZnTHOPP layer.

Upon the formation of a $\mathrm{ZnTHOPP} / \mathrm{H}_{2} \mathrm{TMPyP}$ heterojunction, the ZnTHOPP layer is fully depleted at $V_{a}=0 \mathrm{~V}$, even for a ZnTHOPP layer with the largest thickness (18 $\mathrm{nm})$. So far there have been several reports of relatively large depletion regions for organic systems $(>40 \mathrm{~nm}),{ }^{23-25,29,30}$ but these barriers were formed upon contacting an organic material with a metal with a low work function, i.e., aluminum. By contrast, we assign the formation of the observed space charge region to the contact of a $p$ - and $n$-type porphyrin layer.

Several authors ${ }^{31,32}$ correlated the ionization potentials of various phthalocyanines in thin films to their redoxpotentials using He I photoelectron spectra (UPS). From these studies it turned out that molecular materials with the highest occupied molecular orbitals (HOMO's) at $\leqslant 6.3 \mathrm{eV}$ vs vacuum behave as $p$-type materials, whereas materials with HOMO energies $\geqslant 6.5 \mathrm{eV}$ vs vacuum behave as $n$-type materials. Upon comparison of the redoxpotentials of these films with those of the porphyrin films in this work, we conclude that our results are consistent with a $p$-type character of the ZnTHOPP and an $n$-type character of a $\mathrm{H}_{2}$ TMPyP layer (Table I).

$n$-type behavior of porphyrins with pyridyl substituents similar to $\mathrm{H}_{2}$ TMPyP has been proposed previously ${ }^{33,34}$ based on $i / V$ curves and electrochemical measurements. Naturally occurring defects in layers consisting of porphyrins equipped with pyridyl groups have been suggested as the source of an excess electrons. ${ }^{33}$ By contrast, the interaction of oxygen with porphyrins with a low oxidation potential, such as ZnTHOPP, is expected to produce an excess of holes ${ }^{20}$ resulting in $p$-type behavior. Note that all Mott-Schottky plots have been recorded at $10 \mathrm{kHz}$, five orders of magnitude higher than used by a number of other works, ${ }^{23-25}$ where low analyzing frequencies had to be applied, presumably due to the extremely low mobility of the charge carriers in these materials. 
Upon illumination of the cell the values of the components of the equivalent circuits $C, R_{s}$, and $R_{p}$ do not change significantly. This indicates that the rate constant for recombination of photogenerated electron-hole pairs is fast compared to the analyzing frequency of $10 \mathrm{kHz}$.

\section{B. Photoelectric measurements}

To obtain more evidence for an adequate model, applying to the porphyrin heterojunctions we also measured their photoelectric properties. By changing the individual thicknesses, the extent and nature of the photoactive region of the junction can be determined. ${ }^{11}$ For this purpose absorption spectra and photocurrent action spectra of the junctions are compared.

All action spectra of ITO/ZnTHOPP/ $\mathrm{H}_{2} \mathrm{TMPyP} / \mathrm{Hg}$ cells at $V_{a}=0 \mathrm{~V}$ contain contributions of both the ZnTHOPP and $\mathrm{H}_{2}$ TMPyP layers (see Sec. III). A stepwise increase of the ZnTHOPP layer thickness up to a factor 3 decreases the photocurrent, but leaves the shape of the photocurrent action spectrum unaffected [Figs. 6(b) and 6(d)]. Increasing the $\mathrm{H}_{2}$ TMPyP layer by more than threefold also results in a lowering of the photocurrent, in addition to a slight change in the photocurrent action spectrum at short wavelengths. Since the mercury back contact is expected to reflect the transmitted light efficiently, the $\mathrm{H}_{2}$ TMPyP layer acts as a filter, resulting in the observed small change in the photocurrent action spectrum.

So far, we have assumed that the investigated photodiode is ideal, i.e., $R_{\mathrm{sh}} \rightarrow \infty$ and $R_{s} \rightarrow 0$. It is known, however, that electropolymerized porphyrin films have low conductivities. ${ }^{26,35,36}$ In addition, there may be photoconduction, contributing to the photocurrent action spectrum. ${ }^{20,26}$ From the different slopes of the $i / V$ curve at different light intensities, it can be concluded ${ }^{22}$ that photoconduction indeed occurs. Comparing the different action spectra [Figs. 6(b) and 6(d)], the contribution of the photoconduction to the action spectra can only be relatively small, however, since the action spectra do not show significant changes, if the thickness of the individual layers is varied.

The above-mentioned results can be interpreted as follows.

The finding that an increase of the layer thickness (and thus of the depletion thickness) produces a lower photocurrent could be caused by the high resistivity of the organic material, overshadowing the increase of the photocurrent. However, the photocurrent action spectra (Fig. 6) demonstrate that the relative contributions of both layers do not change upon increasing of the layer thickness of either one or of both layers. This implies that the photoactive part of the cell must be relatively narrow and independent of the layer thickness. Therefore we conclude that charge separation occurs entirely at the interface of both porphyrin layers. At increasing thickness the photocurrent is lowered as a result of the filter effect of the nonphotoactive bulk material and by the increasing Ohmic resistance.

This implies that in the organic bulk layer possible production of electron and holes by optical excitation of the material is expected to be followed by fast recombination. On the other hand, optical excitation of the interface may lead to effective photoinduced charge separation and eventually to a photocurrent.

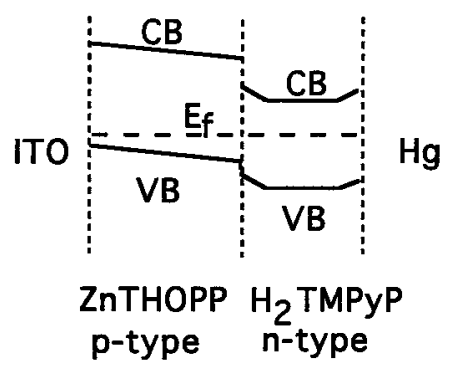

FIG. 7. Energy band diagram for an ITO/ZnTHOPP/ $\mathrm{H}_{2} \mathrm{TMPyP} / \mathrm{Hg}$ cell in the dark.

These conclusions are confirmed by calculations based on the Onsager theory, ${ }^{37-39}$ which predicts that in a homogeneous organic layer with a low value of $\varepsilon_{r}$ photoinduced charge separation into free electrons and holes does not occur due to strong Coulombic interaction. This is in contrast with inorganic semiconductors, where electrons in the conduction band can have diffusion lengths of several micrometers or more. ${ }^{22}$

If we take into account results from independent optical studies on porphyrin heterodimers with similar redox potentials in a medium with low dielectric constant, ${ }^{40}$ efficient photoinduced charge separation can also be expected at the interface between both porphyrin layers in the heterojunction. Since at the interface of the heterojunction both types of porphyrins are in close contact with each other, structures similar to heterodimers as in solution can be formed. The presence of these interfacial species is confirmed by the resemblance of the heterojunction photocurrent action spectrum and the absorption spectrum of $\mathrm{ZnTHOPP} / \mathrm{H}_{2} \mathrm{TMPyP}$ heterodimers. ${ }^{8}$

Following charge separation the photogenerated electronhole pair at the interface can recombine to the ground state or by consecutive dissociation separate into free charge carriers, eventually leading to charge collection by the electrodes. In an organic film with $\varepsilon_{r} \approx 4.5$ and thus a relatively large Coulombic attraction between electrons and holes, ${ }^{41}$ consecutive dissociation of the electron-hole pair competes with recombination to the ground state. However, the internal electric field present in the depletion layer causes the photoinduced charge carriers generated at the interface to drift to the electrodes, resulting in charge collection.

The resulting energy diagram for the investigated heterojunctions is shown in Fig. 7. The energy gaps of 2.0 and 1.8 $\mathrm{eV}$ for ZnTHOPP and $\mathrm{H}_{2}$ TMPyP, respectively, correspond to the lowest $S_{0}-S_{1}$ excitation energy. The valence band energies at 5.4 and $6.0 \mathrm{eV}$ for ZnTHOPP and $\mathrm{H}_{2}$ TMPyP are related to their respective oxidation potentials. ${ }^{20}$ From the impedance measurements we conclude that the $p$-type layer and to a smaller extent the $n$-type layer are in depletion. At the interface different energy steps in the valence and conduction bands are present. Whereas the $\mathrm{H}_{2} \mathrm{TMPyP} / \mathrm{Hg}$ interface shows an $n$-type band bending, the ZnTHOPP/ITO interface forms an Ohmic contact.

Summarizing, the discussion, we suggest that a combination of the $p / n$ and the interface models as described in the Introduction and Fig. 7 adequately explains porphyrin heterojunctions. 
Regarding the heterojunction interface as being built from $\mathrm{ZnTHOPP} / \mathrm{H}_{2}$ TMPyP heterodimers with similar geometry as in solution ${ }^{40}$ photoinduced charge separation in these dimers results in the creation of a dipole with $\mu=17 \mathrm{D}$, if both molecules are considered as point charges. Upon applying an electric field of $1.5 \times 10^{5} \mathrm{~V} \mathrm{~cm}^{-1}$, along the axis of the dipole, typical for our junction, the ion pair energy is lowered by at most $5.2 \mathrm{meV}$. Since the energy step in the conduction band is almost one order of magnitude higher, the presence of an electric field of the above-mentioned size does not noticeably affect the efficiency for charge separation at the interface. In addition, biasing the cell as for the $i / V$ plot of Fig. 5 is thus not expected to influence the efficiency for charge separation. However, the net electric field over the cell increases the drift of the charge carriers, thus controlling the ratio between the rates of charge transport through the bulk layers of both types of porphyrins and electron-hole recombination.

Improvement of this kind of heterojunction cells can be achieved by reducing the cell thickness, thereby diminishing the optical filter effect and the resistance of the bulk material. The efficiency, however, remains limited by the optical absorption of the interface of both organic layers. So far, exciton diffusion within the bulk layers has not been taken into account. Although the exciton diffusion length cannot easily be obtained experimentally, its increase may greatly enhance the photocurrent. ${ }^{13,42}$

\section{CONCLUSIONS}

A heterojunction consisting of a ZnTHOPP and a H2TMPyP layer forms a depletion layer upon contacting and can be described as a $p / n$ junction, analogously to that for inorganic semiconductors. From Mott-Schottky plots the doping concentration is of the order of $\approx 10^{17} \mathrm{~cm}^{-3}$ for ZnTHOPP layers and $\approx 10^{19} \mathrm{~cm}^{-3}$ for $\mathrm{H}_{2}$ TMPyP layers. Since the photocurrent action spectra are independent of individual layer thickness, we conclude that photoinduced charge separation is confined to the interface of both porphyrin layers.

The internal electric field in the depleted bulk layers causes the photoinduced charged carriers at the interface to drift to the electrodes, leading to charge collection. The photovoltaic characteristics of the junction can be adequately described by combining a $p / n$ and an interface model.

\section{ACKNOWLEDGMENTS}

This investigation was supported by the Netherlands Foundation for Chemical Research (SON) with financial aid of the Netherlands Organization for Scientific Research (NWO). The authors wish to thank C.H.M. Maree for Rutherford backscattering measurements and Dr. B. A. Boukamp for providing impedance spectroscopy software.
*To whom correspondence should be addressed.

${ }^{1}$ A. Kay, R. Humphrybaker, and M. Grätzel, J. Phys. Chem. 98, 952 (1994).

${ }^{2}$ B. A. Gregg and Y. I. Kim, J. Phys. Chem. 98, 2412 (1994).

${ }^{3}$ K. Kalyanasundaram, N. Vlachopoulos, V. Krishan, A. Monnier, and M. Grätzel, J. Phys. Chem. 91, 2342 (1987).

${ }^{4}$ A. Kay and M. Grätzel, J. Phys. Chem. 97, 6272 (1993).

${ }^{5}$ B. O'Regan and M. Grätzel, Nature 334, 737 (1991).

${ }^{6}$ B. A. Gregg, M. A. Fox, and A. J. Bard, J. Phys. Chem. 94, 1586 (1990).

${ }^{7}$ B. A. Gregg, Mol. Cryst. Liq. Cryst. A 257, 219 (1994).

${ }^{8}$ T. J. Savenije, R. B. M. Koehorst, and T. J. Schaafsma, Chem. Phys. Lett. 244, 363 (1995).

${ }^{9}$ D. Wöhrle, L. Kreienhoop, G. Schnurpfeil, J. Elbe, B. Tennigkeit, S. Hiller, and D. Schlettwein, J. Mater. Chem. 5, 1819 (1995).

${ }^{10}$ D. Wöhrle, B. Tennigkeit, J. Elbe, L. Kreienhoop, and G. Schnurpfeil, Mol. Cryst. Liq. Cryst. A 228, 221 (1993).

${ }^{11}$ S. Günster, S. Siebentritt, and D. Meissner, Mol. Cryst. Liq. Cryst. A 230, 351 (1993).

${ }^{12}$ S. Günster, S. Siebentritt, J. Elbe, L. Kreienhoop, B. Tennigkeit, D. Wöhrle, R. Memming, and D. Meissner, Mol. Cryst. Liq. Cryst. A 216, 641 (1992).

${ }^{13}$ N. Karl, A. Bauer, J. Holzapfel, J. Marktanner, M. Mobus, and F. Stolzle, Mol. Cryst. Liq. Cryst. A 252, 243 (1994).

${ }^{14}$ S. Morita, S. B. Lee, A. A. Zakhidov, and K. Yoshino, Mol. Cryst. Liq. Cryst. A 256, 839 (1994).

${ }^{15}$ T. Shimidzu, H. Segawa, F. Wu, and N. Nakayama, J. Photo. Chem. Photo. Biol. A 92, 121 (1995).

${ }^{16}$ J. P. Gong, S. Ohnishi, and Y. Osada, Polym. J. 26, 754 (1994).

${ }^{17}$ A. D. Xia, S. J. Fu, H. B. Pan, X. Y. Zhang, Z. Xu, Q. Liu, and R. K. Yuan, Solid State Commun. 95, 713 (1995).
${ }^{18}$ M. Hiramoto, H. Fujiwara, and M. Yokoyama, J. Appl. Phys. 72, 3781 (1992).

${ }^{19}$ C. W. Tang, Appl. Phys. Lett. 48, 183 (1986).

${ }^{20}$ J. Simon and J. Andre, Molecular Semiconductors (SpringerVerlag, Berlin, 1985).

${ }^{21}$ K. Yamashita, Y. Harima, and H. Iwashima, J. Phys. Chem. 91, 3055 (1987).

${ }^{22}$ S. M. Sze, Physics of Semiconductors Devices (Wiley, New York, 1981).

${ }^{23}$ Y. Harima, T. Kodaka, H. Okazaki, Y. Kunugi, K. Yamashita, H. Ishii, and K. Seki, Chem. Phys. Lett. 240, 345 (1995).

${ }^{24}$ Y. Harima, K. Takeda, and K. Yamashita, J. Phys. Chem. Solids 56, 1223 (1995).

${ }^{25}$ C. Nasr, S. Hotchandani, H. Kassi, S. Nsengiyumva, and R. M. Leblanc, Sol. Energ. Mater. Sol. Cells 36, 261 (1995).

${ }^{26}$ C. H. M. Marée, S. J. Roosendaal, T. J. Savenije, R. E. I. Schropp, T. J. Schaafsma, and F. Habraken, J. Appl. Phys. 80, 3381 (1996).

${ }^{27}$ G. Frank and H. Koestin, Appl. Phys. 197, A27 (1982).

${ }^{28}$ D. Lincot and R. O. Borges, J. Electrochem. Soc. 139, 1880 (1992).

${ }^{29}$ E. J. Lous, P. W. M. Blom, L. W. Molenkamp, and D. M. Deleeuw, Phys. Rev. B 51, 17251 (1995).

${ }^{30}$ I. H. Campbell, D. L. Smith, and J. P. Ferraris, Appl. Phys. Lett. 66, 3030 (1995).

${ }^{31}$ J. Bufler, C. Ziegler, and W. Gopel, Synth. Met. 61, 127 (1993).

${ }^{32}$ D. Schlettwein and N. R. Armstrong, J. Phys. Chem. 98, 11771 (1994).

${ }^{33}$ K. Yamashita, Y. Harima, and T. Matsubayashi, J. Phys. Chem. 93, 5311 (1989).

${ }^{34}$ S. Antohe, Phys. Status Solidi A 136, 401 (1993). 
${ }^{35}$ B. A. White and R. W. Murray, J. Am. Chem. Soc. 109, 2576 (1987).

${ }^{36}$ F. Bedioui, J. Devynck, and C. Biedcharreton, Acc. Chem. Res. 28, 30 (1995).

${ }^{37}$ Z. D. Popovic, J. Chem. Phys. 77, 498 (1982).

${ }^{38}$ Z. D. Popovic and A. M. Hor, Mol. Cryst. Liq. Cryst. A 230, 75 (1993).

${ }^{39}$ H. Antoniadis, M. A. Abkowitz, J. A. Osaheni, S. A. Jenekhe, and M. Stolka, Chem. Mater. 6, 63 (1994).
${ }^{40}$ U. Hofstra, R. B. M. Koehorst, and T. J. Schaafsma, Chem. Phys. Lett. 130, 555 (1986).

${ }^{41}$ G. L. Gaines, Michael P. O’Neil, Walter A. Svec, Mark P. Niemczyk, and Michael R. Wasielewski, J. Am. Chem. Soc. 113, 719 (1991).

${ }^{42}$ B. A. Gregg, Appl. Phys. Lett. 67, 1271 (1995).

${ }^{43}$ K. Kalyanasundaram and M. Neumann-Spallart, J. Phys. Chem. 86, 5163 (1982). 